\title{
Impact of preoperative endovascular embolization on immediate meningioma resection outcomes
}

\author{
Michael G. Brandel, BA, Robert C. Rennert, MD, Arvin R. Wali, MAS, \\ David R. Santiago-Dieppa, MD, Jeffrey A. Steinberg, MD, Christian Lopez Ramos, MPH, \\ Peter Abraham, BA, J. Scott Pannell, MD, and Alexander A. Khalessi, MD \\ Department of Neurosurgery, University of California, San Diego, La Jolla, California
}

OBJECTIVE Preoperative embolization of meningiomas can facilitate their resection when they are difficult to remove. The optimal use and timing of such a procedure remains controversial given the risk of embolization-linked morbidity in select clinical settings. In this work, the authors used a large national database to study the impact of immediate preoperative embolization on the immediate outcomes of meningioma resection.

METHODS Meningioma patients who had undergone elective resection were identified in the National (Nationwide) Inpatient Sample (NIS) for the period 2002-2014. Patients who had undergone preoperative embolization were propensity score matched to those who had not, adjusting for patient and hospital characteristics. Associations between preoperative embolization and morbidity, mortality, and nonroutine discharge were investigated.

RESULTS Overall, 27,008 admissions met the inclusion criteria, and 633 patients $(2.34 \%)$ had undergone preoperative embolization and $26,375(97.66 \%)$ had not. The embolization group was younger ( 55.17 vs 57.69 years, $p<0.001$ ) with a lower proportion of females (63.5\% vs $69.1 \%, p=0.003)$, higher Charlson Comorbidity Index $(p=0.002)$, and higher disease severity $(p<0.001)$. Propensity score matching retained 413 embolization and 413 nonembolization patients. In the matched cohort, preoperative embolization was associated with increased rates of cerebral edema $(25.2 \%$ vs $17.7 \%$, $p=0.009)$, posthemorrhagic anemia or transfusion $(21.8 \%$ vs $13.8 \%, p=0.003)$, and nonroutine discharge $(42.8 \%$ vs $35.7 \%, p=0.039)$. There was no difference in mortality $(\leq 2.4 \%$ vs $\leq 2.4 \%, p=0.82)$. Among the embolization patients, the mean interval from embolization to resection was 1.49 days. On multivariate analysis, a longer interval was significantly associated with nonroutine discharge $(O R 1.33, p=0.004)$ but not with complications or mortality.

CONCLUSIONS Relative to meningioma patients who do not undergo preoperative embolization in the same admission, those who do have higher rates of cerebral edema and nonroutine discharge but not higher rates of stroke or death. Thus, meningiomas requiring preoperative embolization represent a distinct clinical entity that requires prolonged, more complex care. Further, among embolization patients, the timing of resection did not affect the risk of in-hospital complications, suggesting that the timing of surgery can be determined according to surgeon discretion.

https://thejns.org/doi/abs/10.3171/2018.1.FOCUS17751

KEY WORDS meningioma; embolization; resection; cerebral edema; timing; discharge disposition

$\mathrm{M}$ ENINGIOMAS are frequently hypervascular, and preoperative embolization of dural feeding arteries, especially for large tumors or lesions with surgically inaccessible vascular supplies, can facilitate resection and decrease operative blood loss and surgical complications. ${ }^{67,711,13,15,16,25,27,28}$ Nonetheless, the ideal use of preoperative meningioma embolization is controversial ${ }^{34}$ as it can also lead to edema, hemorrhage, stroke, and cranial nerve palsies. ${ }^{20,23,30}$ Nonneurological complications related to endovascular therapy can occur as well and include

ABBREVIATIONS APR-DRG = All-Patient Refined Diagnosis-Related Group; $\mathrm{CCI}=$ Charlson Comorbidity Index; HCUP $=$ Healthcare Cost and Utilization Project; NIS = National (Nationwide) Inpatient Sample.

SUBMITTED December 1, 2017. ACCEPTED January 5, 2018.

INCLUDE WHEN CITING DOI: 10.3171/2018.1.FOCUS17751. 
groin hematoma, femoral pseudoaneurysm, and arteriovenous fistula. ${ }^{22}$ Overall complication rates up to $8.3 \%$ have been reported in embolization for meningiomas. ${ }^{13}$

The optimal time interval between tumor embolization and resection is also unknown. Some studies have recommended a minimum of 24 hours if the goal is to simply maximize tumor devascularization and reduce operative blood loss and at least a week when trying to optimize tumor resectability and decrease edema. ${ }^{10,19,33}$ In contrast, other authors have suggested intervals of less than a week to reduce the opportunity for tumor revascularization..$^{26,30}$ In the current work, using a large national database, we studied the impact of immediate preoperative embolization on the immediate outcomes of meningioma resection.

\section{Methods}

A retrospective observational study was performed using the National (Nationwide) Inpatient Sample (NIS) for the period between 2002 and 2014. The NIS is a database publicly available through the Healthcare Cost and Utilization Project (HCUP; https://www.hcup-us.ahrq.gov/ nisoverview.jsp). It is the largest administrative all-payer database in the US, representing a $20 \%$ stratified sample of all US hospital discharges. Patient diagnoses and treatments are recorded using International Classification of Diseases, Ninth Revision, Clinical Modification (ICD-9CM) codes.

\section{Inclusion and Exclusion Criteria}

The database was queried for all meningioma patients (diagnosis codes: 192.1, 225.2, 237.6) who had undergone craniotomy (procedure code: 01.51). Patients undergoing tumor embolization (procedure code: 39.72 ) in the same admission were identified. The NIS provides a "PRDAYn" variable that identifies on which day of hospitalization each procedure occurs. Therefore, patients with a PRDAYn missing for embolization or resection or patients who had an embolization day following the resection day were excluded in order to identify the preoperative embolization patients.

The primary exposure of interest was preoperative embolization for meningioma. Patient variables included tumor histology (benign or malignant), age, sex, race (white, black, Hispanic, Asian or Pacific Islander, or other), Charlson Comorbidity Index (CCI), insurance status (Medicare or private, Medicaid, or no coverage), and zip code income quartile. Admissions were categorized as elective or nonelective. The All-Patient Refined Diagnosis-Related Group (APR-DRG) index was used to represent disease severity. ${ }^{3}$ Hospital variables included region (Northeast, Midwest, South, West), location and teaching status (rural, urban nonteaching, urban teaching), and size (small, medium, or large).

Studied outcomes included morbidity, mortality, and discharge disposition. Complications were derived from previously defined adverse events of meningioma resection $^{1}$ and endovascular embolization, including hematoma complicating a procedure, cerebral infarction or hemorrhage, hydrocephalus, cerebral edema, cranial nerve palsy, meningitis or cerebral venous thrombosis, venous embo- lism, blood transfusion, and mechanical ventilation. Discharge disposition was categorized as routine, nonroutine (discharge to skilled nursing facility, acute rehabilitation facility, hospice, short-term hospital, or home health care), or in-hospital death.

\section{Statistical Analysis}

Statistical analysis was performed using Stata/MP version 14.1 (StataCorp LLC). Continuous variables are presented as the means \pm standard deviations, and categorical variables are presented as counts with corresponding percentages. Independent samples t-tests and Wilcoxon ranksum tests were used to detect group differences for normally and nonnormally distributed continuous variables, respectively. The chi-square test was used for categorical variables, and ordinal logistic regression was used for ordinal variables. Multivariate logistic regression analyses were completed to determine the impact of the interval between embolization and resection on these outcomes. Statistical significance was defined as $\alpha=0.05$, and all tests were 2-sided. In accordance with the HCUP data use agreement, cells containing $\leq 10$ patients are not reported as a patient privacy precaution.

Given significant differences between the embolization and nonembolization patient cohorts, we used propensity score matching to adjust for differences in patient and hospital characteristics. Multivariate logistic regression was used to estimate the propensity of preoperative embolization (compared with no preoperative embolization). Covariates were selected a priori and included age, sex, race, insurance status, zip code income quartile, CCI, APRDRG index, elective status of the admission, hospital size, hospital region, hospital location, and hospital teaching status. Matched propensity score analysis was completed with a 1:1 nearest neighbor algorithm without replacement using the TEFFECTS and PSMATCH2 software modules in Stata. ${ }^{14}$ These matching methods were selected to minimize bias. ${ }^{2}$ Patients who had undergone preoperative embolization were then matched to patients who had not, according to the propensity score. Following propensity score matching, rates of adverse outcomes were compared using chi-square tests.

\section{Results}

Overall, 27,008 meningioma admissions met the inclusion criteria, and 633 patients $(2.34 \%)$ had undergone preoperative embolization and 26,375 (97.66\%) had not. Baseline characteristics for both the overall and the propensity score-matched cohorts are shown in Tables 1 and 2 . Several baseline differences were observed in the overall cohort, including a lower age (55.17 vs 57.69 years, $\mathrm{p}$ $<0.001)$ and a smaller proportion of females $(63.5 \%$ vs $69.1 \%, \mathrm{p}=0.003$ ) among the embolization patients. The embolization patients also had higher CCIs (OR 1.27, $\mathrm{p}$ $=0.002)$ and APR-DRG disease severity (OR 1.68, $\mathrm{p}<$ $0.001)$.

\section{Unmatched Cohort}

In the overall cohort, preoperative embolization was associated with significantly increased rates of hematoma 
TABLE 1. Patient and hospital characteristics in the entire study cohort

\begin{tabular}{|c|c|c|c|}
\hline Variable & No Embolization & Embolization & $\mathrm{p}$ Value \\
\hline No. of patients & 26,375 & 633 & \\
\hline Mean age in yrs & $57.6872 \pm 14.7214$ & $55.1738 \pm 14.2948$ & $<0.001$ \\
\hline Sex & & & 0.003 \\
\hline Male & $8,102(30.9)^{*}$ & $231(36.5)$ & \\
\hline Female & $18,127(69.1)^{*}$ & $402(63.5)$ & \\
\hline Race & & & $<0.001$ \\
\hline White & $15,970(72.7)^{*}$ & $333(62.9)^{*}$ & \\
\hline Black & $2,458(11.2)^{*}$ & $60(11.3)^{*}$ & \\
\hline Hispanic & $1,972(9.0)^{*}$ & $60(11.3)^{*}$ & \\
\hline $\begin{array}{l}\text { Asian or Pacific } \\
\text { Islander }\end{array}$ & $782(3.6)^{*}$ & $42(7.9)^{\star}$ & \\
\hline Other & $790(3.6)^{*}$ & $34(6.4)^{*}$ & \\
\hline Insurance & & & 0.001 \\
\hline $\begin{array}{c}\text { Medicare or } \\
\text { private }\end{array}$ & $22,237(87.6)^{*}$ & $500(82.8)^{*}$ & \\
\hline Medicaid & $2,252(8.9)^{\star}$ & $72(11.9)^{*}$ & \\
\hline None & $888(3.5)^{*}$ & $32(5.3)^{*}$ & \\
\hline $\begin{array}{l}\text { Zip code income } \\
\text { quartile }\end{array}$ & & & 0.008 \\
\hline 1 & $4,408(22.3)^{*}$ & $122(19.8)^{*}$ & \\
\hline 2 & $4,889(24.8)^{*}$ & $128(20.8)^{*}$ & \\
\hline 3 & $5,090(25.8)^{*}$ & $168(27.3)^{*}$ & \\
\hline 4 & $5,340(27.1)^{*}$ & $198(32.1)^{*}$ & \\
\hline $\mathrm{CCl}$ & & & 0.008 \\
\hline 0 & $16,122(61.1)$ & $351(55.5)$ & \\
\hline $1-2$ & $8,230(31.2)$ & $219(34.6)$ & \\
\hline$>2$ & $2,023(7.7)$ & $63(10.0)$ & \\
\hline Severity of illness & & & $<0.001$ \\
\hline $\begin{array}{l}\text { Minor loss of } \\
\text { function }\end{array}$ & $8,307(38.8)^{*}$ & $179(28.3)^{*}$ & \\
\hline $\begin{array}{l}\text { Moderate loss of } \\
\text { function }\end{array}$ & $8,355(39.1)^{\star}$ & $242(38.3)^{*}$ & \\
\hline $\begin{array}{l}\text { Major loss of } \\
\text { function }\end{array}$ & $3,443(16.1)^{*}$ & $151(23.9)^{*}$ & \\
\hline $\begin{array}{l}\text { Extreme loss of } \\
\text { function }\end{array}$ & $1,278(6.0)^{*}$ & $60(9.5)^{*}$ & \\
\hline Histology & & & 0.88 \\
\hline Benign & $25,028(95.7)^{*}$ & $599(95.5)^{*}$ & \\
\hline Malignant & $1,137(4.3)^{*}$ & $28(4.5)^{*}$ & \\
\hline Admission type & & & $<0.001$ \\
\hline Nonelective & $5,479(25.4)^{*}$ & $285(45.3)^{*}$ & \\
\hline Elective & $16,055(74.6)^{*}$ & $344(54.7)^{*}$ & \\
\hline Hospital region & & & $<0.001$ \\
\hline Northeast & $4,565(18.7)^{*}$ & $91(16.3)^{*}$ & \\
\hline Midwest & $4,466(18.3)^{*}$ & $81(14.5)^{*}$ & \\
\hline South & $9,162(37.5)^{*}$ & $171(30.7)^{*}$ & \\
\hline West & $6,208(25.4)^{*}$ & $214(38.4)^{*}$ & \\
\hline
\end{tabular}

CONTINUED IN NEXT COLUMN »
» CONTINUED FROM PREVIOUS COLUMN

TABLE 1. Patient and hospital characteristics in the entire study cohort

\begin{tabular}{cccc}
\hline Variable & No Embolization & Embolization & p Value \\
\hline $\begin{array}{c}\text { Location \& teaching } \\
\text { status of hospital }\end{array}$ & & & $<0.001$ \\
\hline $\begin{array}{c}\text { Urban teach- } \\
\text { ing }\end{array}$ & $18,708(77.1)^{*}$ & $501(89.9)^{*}$ & \\
\hline $\begin{array}{c}\text { Urban non- } \\
\text { teaching }\end{array}$ & $4,990(20.6)^{*}$ & $56(10.1)^{*}$ & \\
\hline Rural & $557(2.3)^{*}$ & $\leq 10(\leq 1.8)^{*}$ & \\
\hline Bed size of hospital & & & $<0.001$ \\
\hline Large & $18,684(77.0)^{*}$ & $465(83.5)^{*}$ & \\
\hline Medium & $4,100(16.9)^{*}$ & $51(9.2)^{*}$ & \\
\hline Small & $1,471(6.1)^{*}$ & $41(7.4)^{*}$ & \\
\hline
\end{tabular}

Values expressed as the mean \pm standard deviation or as number (\%), unless indicated otherwise.

* Data missing for some cases; therefore, values do not reflect total study population.

complicating a procedure $(3.6 \%$ vs $1.7 \%, \mathrm{p}<0.001)$, infarction or hemorrhage $(7.6 \%$ vs $3.8 \%, \mathrm{p}<0.001)$, hydrocephalus $(8.8 \%$ vs $4.1 \%, \mathrm{p}<0.001)$, cerebral edema $(27.6 \%$ vs $11.8 \%, \mathrm{p}<0.001)$, meningitis or cerebral venous thrombosis $(\leq 1.6 \%$ vs $0.6 \%, p=0.049)$, and venous embolism (3.8\% vs $1.8 \%, \mathrm{p}<0.001)$. Embolization patients also had higher rates of posthemorrhagic anemia or transfusion $(21.8 \%$ vs $11.4 \%, \mathrm{p}<0.001)$, mechanical ventilation $(9.0 \%$ vs $5.6 \%, \mathrm{p}<0.001)$, and nonroutine discharge $(42.0 \%$ vs $33.3 \%, \mathrm{p}<0.001)$. There were no differences in the rates of cranial nerve palsy or death (Table 3).

\section{Interval Analysis}

Univariate and multivariate logistic regression analyses restricted to embolization patients were completed to determine the impact of the interval (days) before resection on adverse outcomes. The mean interval was 1.49 days (range 0-20 days). Covariates included the patient and hospital factors previously described. On univariate analysis, a longer interval was significantly associated with an increased risk for infarction or hemorrhage (OR 1.14, $\mathrm{p}$ $=0.022)$ and nonroutine discharge (OR 1.31, p < 0.001). On adjusted analysis, only the association with nonroutine discharge remained significant $(\mathrm{OR} 1.33, \mathrm{p}=0.004)$.

\section{Matched Cohort}

After 1:1 propensity score matching, 413 embolization patients and 413 nonembolization patients were retained for comparison (Table 2). In this matched cohort, preoperative embolization was associated with increased rates of cerebral edema ( $25.2 \%$ vs $17.7 \%, \mathrm{p}=0.009)$, posthemorrhagic anemia or transfusion (21.8\% vs $13.8 \%, \mathrm{p}=0.003)$, and nonroutine discharge ( $42.8 \%$ vs $35.7 \%, \mathrm{p}=0.039$ ). There were no other significant associations (Table 4).

\section{Discussion}

Using the NIS database, we completed a retrospec- 
TABLE 2. Patient and hospital characteristics in the propensity score-matched sample

\begin{tabular}{|c|c|c|c|}
\hline Variable & $\begin{array}{c}\text { No } \\
\text { Embolization }\end{array}$ & Embolization & $\begin{array}{c}p \\
\text { Value }\end{array}$ \\
\hline No. of patients & 413 & 413 & \\
\hline Mean age in yrs & $54.5036 \pm 15.1125$ & $55.7554 \pm 13.934$ & 0.22 \\
\hline Sex & & & 0.83 \\
\hline Male & $149(36.1)$ & $152(36.8)$ & \\
\hline Female & $264(63.9)$ & $261(63.2)$ & \\
\hline Race & & & 0.26 \\
\hline White & $265(64.2)$ & $260(63.0)$ & \\
\hline Black & $52(12.6)$ & $53(12.8)$ & \\
\hline Hispanic & $56(13.6)$ & 46 (11.1) & \\
\hline $\begin{array}{l}\text { Asian or Pacific } \\
\text { Islander }\end{array}$ & $19(4.6)$ & $34(8.2)$ & \\
\hline Other & $21(5.1)$ & $20(4.8)$ & \\
\hline Insurance & & & 0.90 \\
\hline Medicare or private & $342(82.8)$ & $344(83.3)$ & \\
\hline Medicaid & $47(11.4)$ & 48 (11.6) & \\
\hline None & $24(5.8)$ & $21(5.1)$ & \\
\hline $\begin{array}{l}\text { Zip code income } \\
\text { quartile }\end{array}$ & & & 0.85 \\
\hline 1 & $93(22.5)$ & $83(20.1)$ & \\
\hline 2 & $93(22.5)$ & $95(23.0)$ & \\
\hline 3 & $104(25.2)$ & $105(25.4)$ & \\
\hline 4 & $123(29.8)$ & $130(31.5)$ & \\
\hline $\mathrm{CCl}$ & & & 0.18 \\
\hline 0 & $249(60.3)$ & $238(57.6)$ & \\
\hline $1-2$ & $135(32.7)$ & $131(31.7)$ & \\
\hline$>2$ & $29(7.0)$ & $44(10.7)$ & \\
\hline Severity of illness & & & 0.71 \\
\hline $\begin{array}{l}\text { Minor loss of func- } \\
\text { tion }\end{array}$ & $109(26.4)$ & $114(27.6)$ & \\
\hline $\begin{array}{l}\text { Moderate loss of } \\
\text { function }\end{array}$ & $177(42.9)$ & $161(39.0)$ & \\
\hline $\begin{array}{l}\text { Major loss of func- } \\
\text { tion }\end{array}$ & $91(22.0)$ & $97(23.5)$ & \\
\hline $\begin{array}{l}\text { Extreme loss of } \\
\text { function }\end{array}$ & $36(8.7)$ & $41(9.9)$ & \\
\hline Histology & & & 0.51 \\
\hline Benign & $396(95.9)$ & $392(94.9)$ & \\
\hline Malignant & $17(4.1)$ & $21(5.1)$ & \\
\hline Admission type & & & 0.57 \\
\hline Nonelective & $185(44.8)$ & $177(42.9)$ & \\
\hline Elective & $228(55.2)$ & $236(57.1)$ & \\
\hline Hospital region & & & 0.006 \\
\hline Northeast & $62(15.0)$ & 79 (19.1) & \\
\hline Midwest & $53(12.8)$ & $31(7.5)$ & \\
\hline South & $160(38.7)$ & $136(32.9)$ & \\
\hline West & $138(33.4)$ & $167(40.4)$ & \\
\hline
\end{tabular}

CONTINUED IN NEXT COLUMN »
» CONTINUED FROM PREVIOUS COLUMN

TABLE 2. Patient and hospital characteristics in the propensity score-matched sample

\begin{tabular}{cccc}
\hline Variable & $\begin{array}{c}\text { No } \\
\text { Embolization }\end{array}$ & Embolization & $\begin{array}{c}p \\
\text { Value }\end{array}$ \\
\hline $\begin{array}{c}\text { Location \& teaching } \\
\text { status of hospital }\end{array}$ & & 1.00 \\
\hline Urban teaching & $365(88.4)$ & $365(88.4)$ & \\
\hline $\begin{array}{c}\text { Urban non- } \\
\text { teaching }\end{array}$ & $48(11.6)$ & $48(11.6)$ & \\
\hline Bed size of hospital & & & 0.50 \\
\hline Large & $340(82.3)$ & $342(82.8)$ & \\
\hline Medium & $49(11.9)$ & $41(9.9)$ & \\
\hline Small & $24(5.8)$ & $30(7.3)$ & \\
\hline
\end{tabular}

Values expressed as the mean \pm standard deviation or as number (\%), unless indicated otherwise.

tive analysis of meningioma patients who had undergone resection with or without immediate preoperative embolization. Consistent with its goal of decreasing surgical complexity, preoperative embolization was more likely to be performed in patients with comorbid conditions and higher disease severity indices. When adjusting for hospital and patient factors (excluding tumor-specific information not in the NIS database, such as size, location, and arterial feeders), we found that patients who had undergone preoperative embolization had a $47 \%$ increased risk of cerebral edema, $92 \%$ increased risk of posthemorrhagic anemia or transfusion, and 7\% increased risk for nonroutine discharge. In contrast, there were no differences for other complications, such as cranial nerve palsy, cerebral infarction or hemorrhage, and death.

Because preoperative embolization is more likely to be performed for large,${ }^{29}$ vascular meningiomas with difficultto-access feeding arteries, ${ }^{12}$ the increased risks for cerebral edema, blood loss, and adverse discharge are not necessarily surprising. Nonetheless, such tumor characteristics represent a confounding variable by indication, where a variable is associated with both the exposure and the outcome. ${ }^{31,32}$ While our use of propensity score matching minimized confounding of the measured variables available in the NIS database, it did not preclude confounding by unmeasured variables, such as individual surgeon preferences or tumor characteristics. Given this limitation, our data suggest that complex meningiomas thought to require preoperative embolization represent a clinical entity distinct from those meningiomas that appear resectable without preoperative treatment. Nonetheless, preoperative embolization and resection of such complex meningiomas can be safely performed in the majority of cases.

The higher rate of cerebral edema we observed in the embolization patients $(25.2 \%$ vs $17.7 \%$ in the matched cohort) is consistent with rates in prior studies ${ }^{8,21,36,37}$ and likely results from a combination of the increased complexity of tumors selected for embolization and an effect of the embolization itself. ${ }^{34}$ Pretreatment edema exists in up to two-thirds of meningioma patients and varies with tumor location, tumor size, and extent of cortical dam- 
TABLE 3. Outcomes in the full patient sample

\begin{tabular}{lccc}
\hline \multicolumn{1}{c}{ Variable } & No Embolization & Embolization & $p$ Value \\
\hline No. of patients & 26,375 & 633 & \\
\hline Hematoma complicating a procedure & $447(1.7)$ & $23(3.6)$ & $<0.001$ \\
\hline Cerebral infarction or hemorrhage & $1,009(3.8)$ & $48(7.6)$ & $<0.001$ \\
\hline Hydrocephalus or performance of ventriculostomy & $1,082(4.1)$ & $56(8.8)$ & $<0.001$ \\
\hline Cerebral edema & $3,121(11.8)$ & $175(27.6)$ & $<0.001$ \\
\hline Cranial nerve palsy & $621(2.4)$ & $21(3.3)$ & 0.12 \\
\hline Posthemorrhagic anemia or transfusion & $3,001(11.4)$ & $138(21.8)$ & $<0.001$ \\
\hline Meningitis or cerebral venous thrombosis & $166(0.6)$ & $\leq 10(\leq 1.6)$ & 0.049 \\
\hline Venous embolism or placement of IVC filter & $483(1.8)$ & $24(3.8)$ & $<0.001$ \\
\hline Mechanical ventilation & $1,472(5.6)$ & $57(9.0)$ & $<0.001$ \\
\hline Nonroutine discharge & $8,649(33.3)^{*}$ & $260(42.0)^{*}$ & $<0.001$ \\
\hline Death during hospitalization & $366(1.4)$ & $12(1.9 \%)$ & 0.28 \\
\hline
\end{tabular}

IVC = inferior vena cava.

Values expressed as number (\%), unless indicated otherwise.

* Data missing for some cases; therefore, values do not reflect total study population.

age. ${ }^{8,17,18,24}$ Larger meningiomas and those located in the frontal convexity or middle third falx have been shown to have significantly greater edema. ${ }^{24}$ Therefore, while embolization is known to be associated with cerebral edema, ${ }^{34}$ many of the patients in our study probably had baseline edema before embolization or resection. Unfortunately, the timing and cause of this edema cannot be directly ascertained from our data set. However, abnormal imaging results (such as cerebral edema) are only coded for billing and only appear in the NIS database with documented clinical significance, ${ }^{9}$ and those patients with baseline symptomatic edema not reflected in the CCI and APRDRG index were almost certainly more likely to have had deeper or larger tumors that would be selected for preoperative embolization.

To our knowledge, this is the first report of a greater incidence of nonroutine discharge disposition among meningioma patients who underwent preoperative emboliza- tion than that among nonembolized patients. Because this finding persisted on adjusted analysis-unlike complications of embolization, such as stroke or hemorrhage-it probably represents a meaningful clinical impact of the increased complexity of tumors selected for embolization. Therefore, further care of cerebral edema in complex meningioma patients may be required for clinical manifestations such as nausea and vomiting, altered mental status, or decreased respiratory drive. Prolonged care following hospital discharge also probably increases costs for both patients and health care systems and should be considered when planning treatment.

Together, our data suggest that meningiomas selected for preoperative embolization represent a subset of highrisk tumors and that patients with these tumors have extra clinical needs. Surgical and postoperative care for these patients should be planned accordingly and the costs perhaps reimbursed differently than those for simple menin-

TABLE 4. Outcomes in the propensity score-matched patient sample

\begin{tabular}{lccc}
\hline \multicolumn{1}{c}{ Variable } & No Embolization & Embolization & p Value \\
\hline No. of patients & 413 & 413 & 0.057 \\
\hline Hematoma complicating a procedure & $\leq 10(\leq 2.4)$ & $16(3.9)$ & 1.00 \\
\hline Cerebral infarction or hemorrhage & $24(5.8)$ & $24(5.8)$ & 0.45 \\
\hline Hydrocephalus or performance of ventriculostomy & $31(7.5)$ & $37(9.0)$ & 0.009 \\
\hline Cerebral edema & $73(17.7)$ & $104(25.2)$ & 0.84 \\
\hline Cranial nerve palsy & $13(3.1)$ & $14(3.4)$ & 0.003 \\
\hline Posthemorrhagic anemia or transfusion & $57(13.8)$ & $90(21.8)$ & 0.31 \\
\hline Meningitis or cerebral venous thrombosis & $\leq 10(\leq 2.4)$ & $\leq 10(\leq 2.4)$ & 0.43 \\
\hline Venous embolism or placement of IVC filter & $11(2.7)$ & $15(3.6)$ & 0.72 \\
\hline Mechanical ventilation & $41(9.9)$ & $38(9.2)$ & 0.039 \\
\hline Nonroutine discharge & $144(35.7)^{*}$ & $173(42.8)^{*}$ & 0.82 \\
\hline Death during hospitalization & $\leq 10(\leq 2.4)$ & $\leq 10(\leq 2.4)$ & \\
\hline
\end{tabular}

Values expressed as number (\%), unless indicated otherwise.

* Data missing for some cases; therefore, values do not reflect total study population. 
giomas. Future longitudinal studies are needed to determine if there are associations between preoperative embolization and long-term outcomes for meningioma patients.

The interval between embolization and craniotomy is also a controversial topic, with mixed recommendations and evidence for impact on efficacy or patient outcomes. ${ }^{4,5,10,12,19,30,35}$ However, embolization and resection are usually completed within 72 hours of each other and within the same hospital stay. ${ }^{11}$ In the current analysis, we identified delayed resection as a risk factor for cerebral infarction or hemorrhage, although this relation did not persist on multivariate analysis. However, there was a significant association between a longer interval and nonroutine discharge on both unadjusted and adjusted analyses. Given that delayed resection does not appear to be associated with an increased risk of in-hospital complications, the timing of surgery following embolization can be largely determined according to surgeon discretion.

There are several limitations to retrospective analyses utilizing a large administrative database as well as the risk of confounding by indication, as discussed above. Specifically, the NIS does not contain information about a patient's baseline neurological status and long-term outcome or about procedural details, such the particle size and type of embolic agent. However, the object of this study was to assess the overall risk of adverse in-hospital outcomes for preoperative embolization patients relative to that for nonembolization patients, and therefore we did not require this information. An additional limitation related to our study design is our assessment of preoperative embolizations only performed in the same admission as the craniotomy. In some cases, patients undergo embolization and are discharged for variable lengths of time before being readmitted for resection. Although this was probably true for only a minority of cases, these types of patients may have been misclassified as nonembolization patients, likely biasing comparisons between groups toward the null. Large database analyses of meningioma patients would be improved by the availability of longitudinal data on postdischarge complications and tumor recurrence. Furthermore, data on tumor characteristics such as size, feeding arteries, and location would enable more precise matching of embolization and nonembolization patients for analysis.

\section{Conclusions}

Meningiomas requiring preoperative embolization likely represent a distinct clinical entity with greater treatment complexity and higher risks. These findings have important implications for the management of and reimbursement structure for these complex tumors.

\section{Acknowledgments}

The project described was partially supported by the National Institutes of Health Predoctoral Grant No. TL1TR001443 (M.G.B. and P.A.).

\section{References}

1. Ambekar S, Sharma M, Madhugiri VS, Nanda A: Trends in intracranial meningioma surgery and outcome: a Nationwide
Inpatient Sample database analysis from 2001 to 2010. J Neurooncol 114:299-307, 2013

2. Austin PC: Statistical criteria for selecting the optimal number of untreated subjects matched to each treated subject when using many-to-one matching on the propensity score. Am J Epidemiol 172:1092-1097, 2010

3. Averill RF, Goldfield NI, Muldoon J, Steinbeck BA, Grant TM: A closer look at all-patient refined DRGs. J AHIMA 73:46-50, 2002

4. Bendszus M, Klein R, Burger R, Warmuth-Metz M, Hofmann E, Solymosi L: Efficacy of trisacryl gelatin microspheres versus polyvinyl alcohol particles in the preoperative embolization of meningiomas. AJNR Am J Neuroradiol 21:255-261, 2000

5. Bendszus M, Martin-Schrader I, Warmuth-Metz M, Hofmann E, Solymosi L: MR imaging- and MR spectroscopyrevealed changes in meningiomas for which embolization was performed without subsequent surgery. AJNR Am J Neuroradiol 21:666-669, 2000

6. Bendszus M, Rao G, Burger R, Schaller C, Scheinemann K, Warmuth-Metz M, et al: Is there a benefit of preoperative meningioma embolization? Neurosurgery 47:1306-1312, 2000

7. Borg A, Ekanayake J, Mair R, Smedley T, Brew S, Kitchen $\mathrm{N}$, et al: Preoperative particle and glue embolization of meningiomas: indications, results, and lessons learned from 117 consecutive patients. Neurosurgery 73 (2 Suppl Operative):ons244-ons252, 2013

8. Carli DF, Sluzewski M, Beute GN, van Rooij WJ: Complications of particle embolization of meningiomas: frequency, risk factors, and outcome. AJNR Am J Neuroradiol 31:152154,2010

9. Centers for Medicare and Medicaid Services, National Center for Health Statistics: ICD-9-CM Official Guidelines for Coding and Reporting. (https://www.cdc.gov/nchs/data/icd/ icd9cm_guidelines_2011.pdf ) [Accessed February 13, 2018]

10. Chun JY, McDermott MW, Lamborn KR, Wilson CB, Higashida R, Berger MS: Delayed surgical resection reduces intraoperative blood loss for embolized meningiomas. Neurosurgery 50:1231-1237, 2002

11. Dean BL, Flom RA, Wallace RC, Khayata MH, Obuchowski NA, Hodak JA, et al: Efficacy of endovascular treatment of meningiomas: evaluation with matched samples. AJNR Am J Neuroradiol 15:1675-1680, 1994

12. Djindjian R, Cophignon J, Théron J, Merland JJ, Houdart R: Embolization by superselective arteriography from the femoral route in neuroradiology. Review of 60 cases. 1 . Technique, indications, complications. Neuroradiology 6:20-26, 1973

13. Dubel GJ, Ahn SH, Soares GM: Contemporary endovascular embolotherapy for meningioma. Semin Intervent Radiol 30:263-277, 2013

14. Garrido MM, Kelley AS, Paris J, Roza K, Meier DE, Morrison RS, et al: Methods for constructing and assessing propensity scores. Health Serv Res 49:1701-1720, 2014

15. Gruber A, Killer M, Mazal P, Bavinzski G, Richling B: Preoperative embolization of intracranial meningiomas: a 17-years single center experience. Minim Invasive Neurosurg 43:18-29, 2000

16. Haider AS, Rana H, Lee LK, Shail MS, Leonard D, Khan U, et al: Large transcalvarial meningioma: surgical resection aided by preoperative embolization. Cureus 9:e1229, 2017

17. Hou J, Kshettry VR, Selman WR, Bambakidis NC: Peritumoral brain edema in intracranial meningiomas: the emergence of vascular endothelial growth factor-directed therapy. Neurosurg Focus 35(6):E2, 2013

18. Ide M, Jimbo M, Kubo O, Yamamoto M, Takeyama E, Imanaga $\mathrm{H}$ : Peritumoral brain edema and cortical damage by meningioma. Acta Neurochir Suppl (Wien) 60:369-372, 1994 
19. Kai Y, Hamada J, Morioka M, Yano S, Todaka T, Ushio Y: Appropriate interval between embolization and surgery in patients with meningioma. AJNR Am J Neuroradiol 23:139-142, 2002

20. Kallmes DF, Evans AJ, Kaptain GJ, Mathis JM, Jensen ME, Jane JA, et al: Hemorrhagic complications in embolization of a meningioma: case report and review of the literature. Neuroradiology 39:877-880, 1997

21. Kasuya H, Shimizu T, Sasahara A, Takakura K: Phenytoin as a liquid material for embolisation of tumours. Neuroradiology 41:320-323, 1999

22. Kominami S, Watanabe A, Suzuki M, Mizunari T, Kobayashi S, Teramoto A: Preoperative embolization of meningiomas with N-butyl cyanoacrylate. Interv Neuroradiol 18:133-139, 2012

23. Lefkowitz M, Giannotta SL, Hieshima G, Higashida R, Halbach V, Dowd C, et al: Embolization of neurosurgical lesions involving the ophthalmic artery. Neurosurgery 43:12981303, 1998

24. Lobato RD, Alday R, Gómez PA, Rivas JJ, Domínguez J, Cabrera A, et al: Brain oedema in patients with intracranial meningioma. Correlation between clinical, radiological, and histological factors and the presence and intensity of oedema. Acta Neurochir (Wien) 138:485-494, 1996

25. Macpherson P: The value of pre-operative embolisation of meningioma estimated subjectively and objectively. Neuroradiology 33:334-337, 1991

26. Manelfe C, Lasjaunias P, Ruscalleda J: Preoperative embolization of intracranial meningiomas. AJNR Am J Neuroradiol 7:963-972, 1986

27. Oka H, Kurata A, Kawano N, Saegusa H, Kobayashi I, Ohmomo T, et al: Preoperative superselective embolization of skull-base meningiomas: indications and limitations. J Neurooncol 40:67-71, 1998

28. Quiñones-Hinojosa A, Kaprealian T, Chaichana KL, Sanai N, Parsa AT, Berger MS, et al: Pre-operative factors affecting resectability of giant intracranial meningiomas. Can J Neurol Sci 36:623-630, 2009

29. Raper DM, Starke RM, Henderson F Jr, Ding D, Simon S, Evans AJ, et al: Preoperative embolization of intracranial meningiomas: efficacy, technical considerations, and complications. AJNR Am J Neuroradiol 35:1798-1804, 2014

30. Richter HP, Schachenmayr W: Preoperative embolization of intracranial meningiomas. Neurosurgery 13:261-268, 1983

31. Rush B, Rousseau J, Sekhon MS, Griesdale DE: Craniotomy versus craniectomy for acute traumatic subdural hematoma in the United States: a national retrospective cohort analysis. World Neurosurg 88:25-31, 2016

32. Salas M, Hofman A, Stricker BH: Confounding by indication: an example of variation in the use of epidemiologic terminology. Am J Epidemiol 149:981-983, 1999

33. Shi ZS, Feng L, Jiang XB, Huang Q, Yang Z, Huang ZS: Therapeutic embolization of meningiomas with Onyx for delayed surgical resection. Surg Neurol 70:478-481, 2008

34. Singla A, Deshaies EM, Melnyk V, Toshkezi G, Swarnkar A, Choi $\mathrm{H}$, et al: Controversies in the role of preoperative embolization in meningioma management. Neurosurg Focus 35(6):E17, 2013

35. Teasdale E, Patterson J, McLellan D, Macpherson P: Subselective preoperative embolization for meningiomas. A radiological and pathological assessment. J Neurosurg 60:506-511, 1984

36. Wakhloo AK, Juengling FD, Van Velthoven V, Schumacher M, Hennig J, Schwechheimer K: Extended preoperative polyvinyl alcohol microembolization of intracranial meningiomas: assessment of two embolization techniques. AJNR Am J Neuroradiol 14:571-582, 1993

37. Yasui K, Shoda Y, Suyama T, Numa Y, Amanouchi YY, Kawamoto K: Preoperative embolization for meningioma using lipiodol. Interv Neuroradiol 4 (Suppl 1):63-66, 1998

\section{Disclosures}

Dr. Pannell has been a consultant for Stryker.

\section{Author Contributions}

Conception and design: all authors. Acquisition of data: Brandel, Lopez Ramos. Analysis and interpretation of data: Brandel, Lopez Ramos. Drafting the article: Brandel, Rennert. Critically revising the article: all authors. Reviewed submitted version of manuscript: all authors. Approved the final version of the manuscript on behalf of all authors: Khalessi. Statistical analysis: Brandel. Administrative/technical/material support: Wali, Santiago-Dieppa, Steinberg, Abraham. Study supervision: Khalessi, Rennert, Santiago-Dieppa, Pannell.

\section{Correspondence}

Alexander A. Khalessi: University of California, San Diego, La Jolla, CA. akhalessi@ucsd.edu. 